unresponsive to antimycotic treatment. Our patient responded well to maintenance fluconazole therapy, and there is no evidence of recurrence 1 year after the initial presentation.

In conclusion, this case illustrates the danger of treating a patient with a presumed diagnosis of idiopathic orbital inflammation with a trial of corticosteroids. ${ }^{7}$ Such an approach masks the true nature of the fungal abscess, delays incisional biopsy for histopathological diagnosis, and increases the risk of progressive dissemination. Although corticosteroids remain the mainstay of treatment for idiopathic orbital inflammation a poor response, recurrence, or abscess formation require a re-evaluation. Coccidioidomycosis, especially in endemic areas, should be considered in the differential diagnosis of any lacrimal gland fossa mass that does not resolve with intravenous antibiotics.

J-R JOU

$S$ PATEL

A A SADUN

Department of Ophthalmology, Doheny Eye Institute, USC School of Medicine, Los Angeles, California

$U S A$

J-R JOU

Department of Ophthalmology, National Taiwa

University School of Medicine, Taipei, Taiwan

Correspondence to: Alfredo A Sadun, $\mathrm{MD}, \mathrm{PhD}$ Doheny Eye Institute, 1450 San Pablo Street, Los Angeles, CA 90033, USA.

Accepted for publication 13 September 1995

1 Rodenbiker HT, Ganley JP. Ocular coccidioidomycosis. Surv Ophthalmol 1980; 24: 263-90.

2 Kwan-Chung KJ. Bennett JE. Medical mycology. Philadelphia: Lea \& Febiger, 1992: 356-96.

3 Jakobiec FA, Yeo JH, Trokel SL, Abbott GF Anderson R, Citrin CM, et al. Combined clinical and computed tomographic diagnosis of primary lacrimal fossa lesions. Am f Ophthalmol 1982; 94: 785-807.

4 Shields CL, Shields JA, Eagle RC, Rathmell JP. Clinicopathologic review of 142 cases of lacrimal gland lesions. Ophthalmology 1989; 96: 431-5.

5 Krohel GB, Krauss HR, Winnick J. Orbital abscess: presentation, diagnosis, therapy, and abscess: presentation, diagnosis, therapy,
sequelae. Ophthalmology 1982; 89: 492-8.

6 Balchunas WR, Quencer RM, Byrne SF Lacrimal gland and fossa masses: evaluation by computed tomography and A-mode echography. Radiology 1983; 149: 751-8.

7 Stewart WB, Kroliel GB, Wright JE. Lacrimal gland and fossa lesions: an approach to diag nosis and management. Ophthalmology 1979; 86: 886-95.

\section{A case of primary orbital melanoma treated by local excision}

EDITOR,-Melanositic tumours of the orbit as a rule are secondary, arising chiefly from the uveal tract and adjacent areas such as conjunctiva, eyelids, nasal sinuses, and intracranial meninges. ${ }^{1}$ Primary orbital melanoma is much less common than these secondary tumours and accounts for less than $1 \%$ of primary orbital neoplasms. ${ }^{2}$

We describe a case of an uncommon slowly progressing well circumscribed primary orbital melanoma. This was treated by primary resection with no evidence of recurrence or metastasis on follow up.

CASE REPORT

A 79-year-old man was admitted to the Ophthalmology Clinic of the University of Cumhuriyet Medical School, Sivas with a 9 year history of progressive tumour of the left eye, which had been increasing in size for

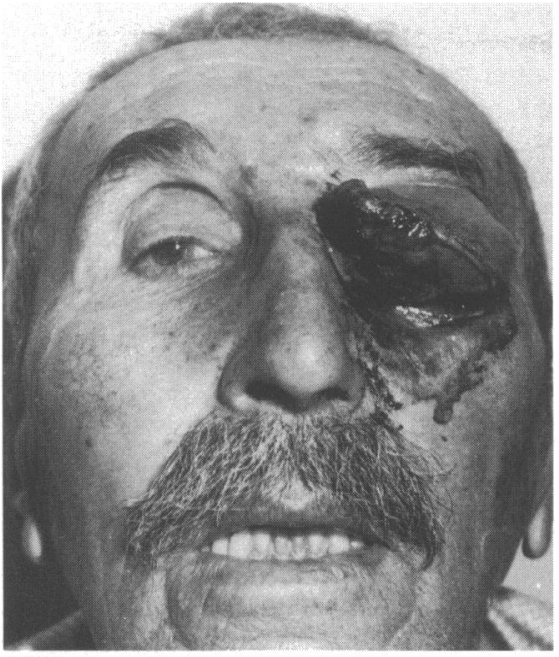

Fig $1 A$

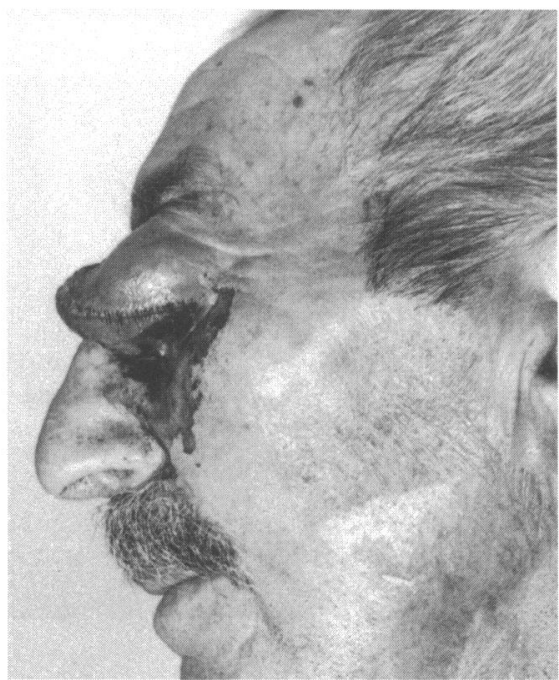

Fig $1 B$

Figure 1 (A) Patient at presentation showing a large mass filling the left orbit. The eyeball was obscured from view. (B) Upper eyelid was grossly distended by the tumour extending approximately $5 \mathrm{~cm}$ anterior to the orbital rim. about 2 years. He had subjective symptoms such as pain, bleeding, and an unbearable smell for about 1 month. He had not sought medical help in this 9 year period. When he was first seen at our clinic, the left upper eyelid was grossly distended by a large bluish tumour mass extending approximately $5 \mathrm{~cm}$ anterior to the orbital rim (Fig 1). On palpation, a semi-soft mass could be felt through the lids, evidently filling the orbit. There was a fragile and bleeding ulcer and necrosis on the anteronasal suface of the tumour. The eyeball was obscured from view, but when the mass was elevated with retractors a vascularised cloudy cornea was seen. He has no light perception in his left eye. The visual acuity of his right eye was $20 / 30$ and there was no significant abnormality except nuclear sclerosis of the lens.

An orbital computed tomographic scan demonstrated a well demarcated non-homogeneous, large mass located anterosuperiorly in the left orbit. The eyeball itself was normal. There was no calcification or bony erosion (Fig 2).

The surgical approach was via incision through the upper eyelid margin. Overlying conjunctiva was intact and it was seen to be easily separable from the tumour. A dark blue pseudoencapsulated mass was easily freed from the globe and other orbital tissues by

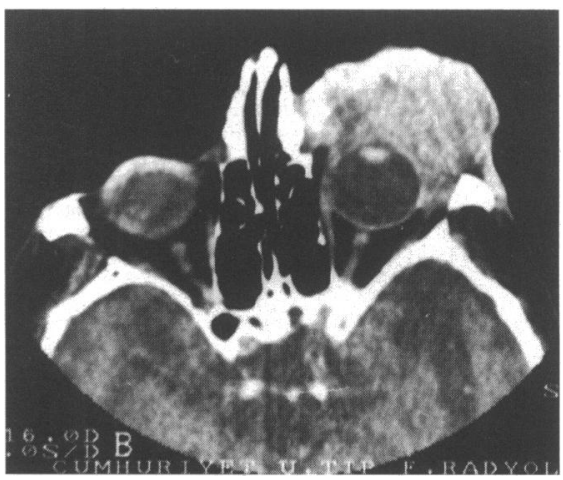

Figure 2 Computed tomography of the orbits show circumscribed mass located anterosuperiorly in the left orbit.

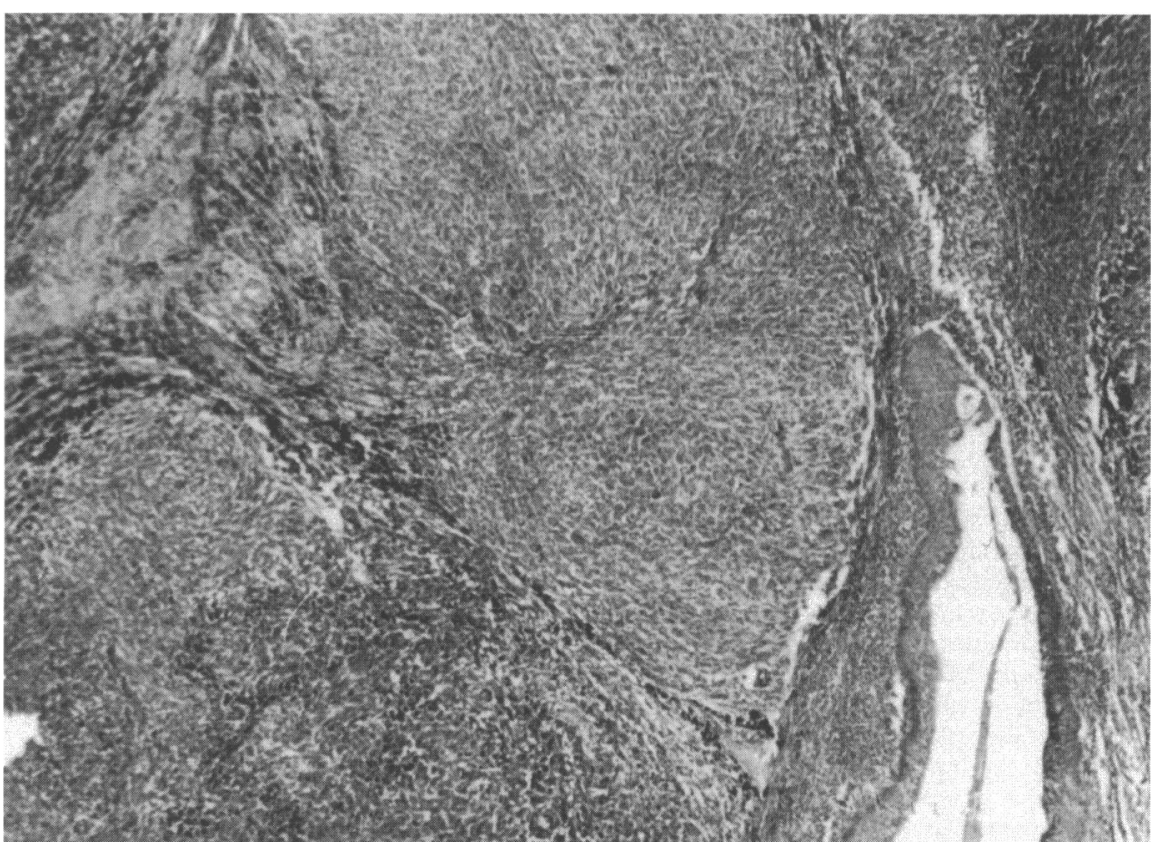

Figure 3 Microscopically it is nodular in configuration, and consists of spindle-shaped cells, some containing melanin. There is no junctional activity in the overlying epithelium. Haematoxylin and eosin, $\times 25$. 

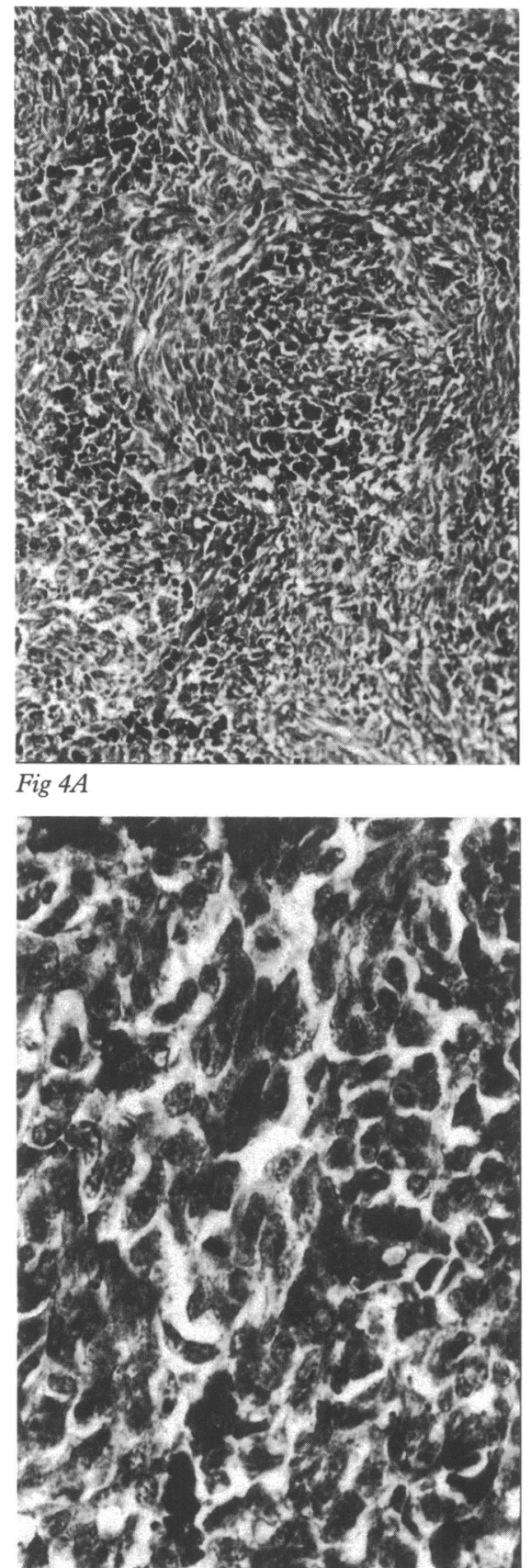

Fig $4 B$

Figure 4 (A) The majority of cells are spindle-shaped but some are epithelioid. Melanin is present in some tumour cells. Haematoxylin and eosin, $\times 50$. (B) High magnification of the tumour cells. Mitotic figures are present.

Haematoxylin and eosin, $\times 100$.

blunt dissection without rupture of the capsule. The mass was excised with the overlying conjunctiva.

There was no visible sign of any abnormal pigmentation or structure in the orbital cavity or the globe.

The tumour was diagnosed as a melanoma. A thorough physical examination demonstrated the absence of cutaneous or mucous membrane melanoma. A complete blood cell count and results of liver enzyme studies, chest roentgenography, and a urinalysis were normal. Computed tomographic scan of the head and body were normal as well. He has been followed for 11 months without evidence of recurrence or metastasis.

Gross pathological examination of the tumour indicated a well circumscribed solid mass $6 \times 4 \times 3 \mathrm{~cm}$ in diameter. The cut surface showed a distinct bimorphic appearance, with

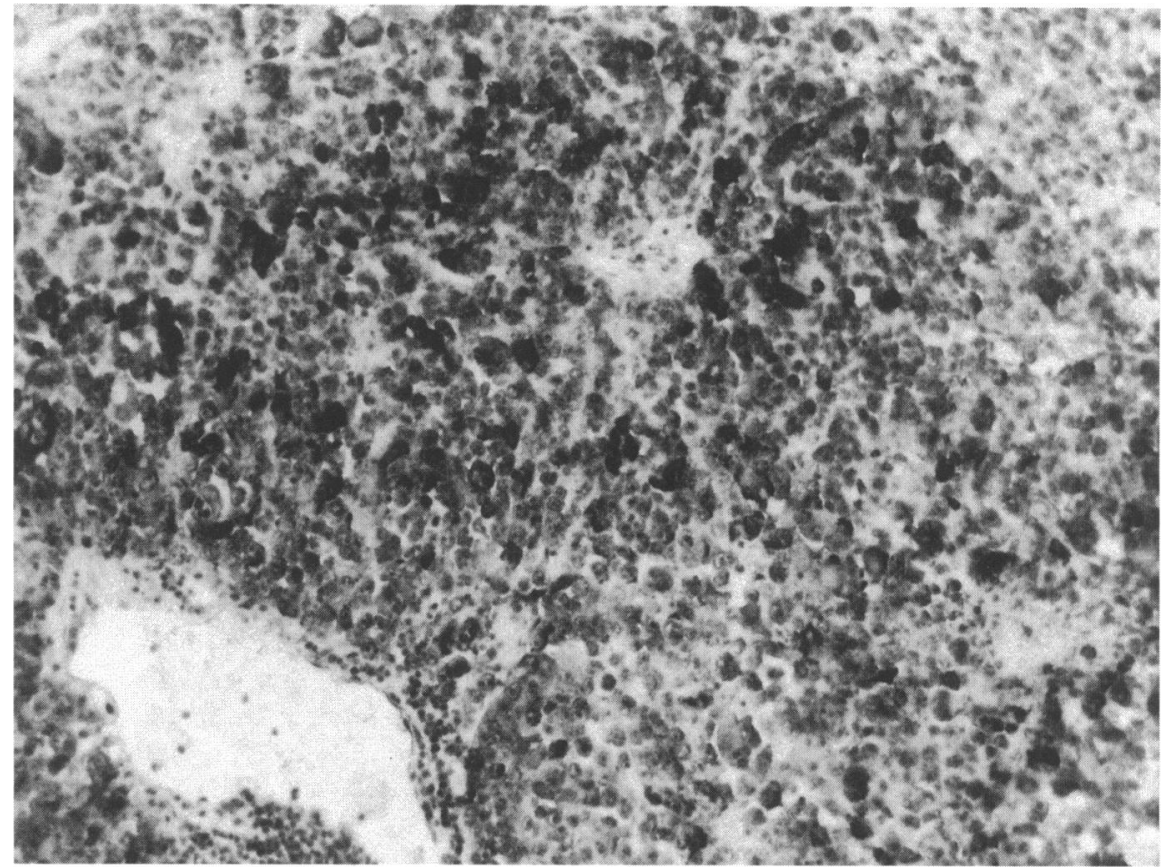

Figure 5 Immunoperoxidase staining for HMB-45 shows melanoma cells. IP, $\times 100$.

a pigmentary component and deeply pigmented areas.

Microscopically, the anterior side of the tumour was covered by conjunctival squamous epithelium. There was a grenz zone (tumour free narrow space) between the tumour and epithelium (Fig 3). There was no junctional activity. The tumour consisted of epithelioid and spindle-shaped cells. Some of these cells show coarsely granular brown cytoplasmic pigmentation. Fontana stain confirmed the melanotic nature of pigmentation, iron stains were negative. Higher power examination of the cells revealed marked pleomorphism, prominent nuclei with eosinophilic macronucleoli, and a few mitotic figures (Fig 4).

On immunohistochemical staining, immunoreactivity for HMB-45 and vimentin was presented, neuron specific enolase and chromogranin were absent. Immunoperoxidase staining for HMB-45 shows melanoma cells (Fig 5).

\section{COMMENT}

Only few cases of primary malignant melanoma of the orbit have been reported. There is not much information on their clinical behaviour but painless proptosis from a diffuse orbital mass is the most common presentation. The duration of symptoms is variable, with some progressing slowly over several years as in our case, ${ }^{2-4}$ while others present rapidly over 1 to 3 months. ${ }^{156}$

Primary orbital melanomas frequently associated with pigmentary disorders such as oculodermal melanocytosis, ocular melanocytosis, and blue naevi. ${ }^{4}$ In our patient, there was no visible associated cutaneous and orbital pigmentary disorders and computed tomographic scan demonstrated a well demarcated tumour. In addition, easy dissection and peeling off the tumour from surrounding structures suggested an encapsulated tumour, such as a cavernous haemangioma.

It is difficult to speculate on the pathogenesis of this primary malignant melanoma of the orbit as melanocytes are not commonly encountered in the orbit and the cellula origin of the orbital melanoma is not clear. The orbital melanocyte, a neural crest derivate, may be found along ciliary nerves, scleral emisserial vessels, or optic nerve leptomeninges. ${ }^{5}$ Tumours may also originate from anomalous deposits associated with periorbital pigmentary disorders. ${ }^{3}$ In our case an ectopic pigmented nidus might have undergone malign transformation

The occurrence of primary orbital melanoma is so rare that it becomes necessary in each case to rule out extension from the globe and metastasis from a more distant focus. ${ }^{3}$ In our case physical examination and laboratory investigations were repeated on his last visit and signs of recurrence and metastasis were not found.

In the treatment of primary orbital melanomas exenteration, exenteration plus radiation, and excision alone have been performed. Exenteration is the treatment of choice of most ophthalmologists for orbital malign melanoma and it may be the best treatment for diffuse lesions, but offers no assurance of a cure. There are two patients reported in the literature with disease free follow up periods of up to 2 and 32 years after the primary resection of an encapsulated tumour, and it is suggested that primary resection, rather than agressive surgery or adjuvant therapy, is probably sufficent for encapsulated tumours. ${ }^{5}$

Although the follow up period in our case was short (11 months), the absence of recurrence or metastasis supports an initial primary resection for circumscribed tumours.

O ELIBOL N YUKSEL Cumhuriyet H R EGILMEZ $S$ ARICI Department of Patholog Cumhuriyet University, Sivas, Turkey B MIZRAK Department of Pathology Ankara University, Ankara, Turkey

Correspondence to: Orhan Elibol, GMK Bulv Onur Ishanı 12/12, Krźllay, Ankara, Turkey.

Accepted for publication 13 September 1995

1 Henderson JW, Farrow GM. Malignant melanoma primary in the orbit: report of a case. Trans Am Acad Ophthalmol Otol 1972; 76: 1487-90. 
2 Shields JA, Bakewell B, Ausburger JJ, Flanagan JC. Classification and incidence of space-occupying of the orbit. Arch Ophthalmol 1984; 102: pying of the

3 Rottino A, Kelly AS. Primary orbital melanoma case report with review of the literature. Arch
Ophthalmol 1942; 27: 934-49.

4 Dutton JI, Anderson RL Schelper RL, Purcell JJ, Tse DT. Orbital malignant melanoma and oculodermal melanocytosis: report of two case and review of the literature. Ophthalmology 1984; 91: 497-507.
5 Rice CD, Brown HH. Primary orbital melanoma associated with orbital melanocytosis. Arch Ophthalmol 1990; 108: 1130-4.

6 Jacobiec FA, Ellsworth R, Tannenbaum M. Primary orbital melanoma. Am $\mathcal{f}$ Ophthalmol 1974; 78: 24-39. 